\title{
LA DESAFIANTE IDEA DE MOLINARI: LA DEFENSA EN RÉGIMEN DE LIBRE COMPETENCIA
}

\author{
JOSÉ HERNÁNDEZ CABRERA*
}

Fecha de recepción: 21 de mayo de 2015.

Fecha de aceptación: 6 de octubre de 2015.

Resumen: Según Gustave de Molinari (1819-1912) todo monopolio es nocivo para los consumidores porque estos reciben peores bienes y a precios más elevados en comparación con lo que sucedería en el libre mercado. No encontramos razones económicas ni lógicas que justifiquen el monopolio estatal de la producción de seguridad y su existencia debería ser explicada por otros medios. La idea de Molinari, que no es otra cosa que llevar la doctrina del laissez faire hasta sus últimas consecuencias, es desafiante porque implica de facto la disolución del Estado tal y como lo concebimos actualmente. Los gobernantes se opondrán, con todos los medios a su alcance, a perder el monopolio coactivo de la producción de seguridad porque perjudica sus intereses, a saber, su poder. Los ejemplos históricos de sociedades sin Estado sólo se han dado a pequeña escala o en grupos sociales primitivos y poco desarrollados. Tal vez, la única producción privada de seguridad, en libre competencia, la veamos en los proyectos free cities o ciudades libres bajo estatuto.

Palabras clave: Molinari, Laissez faire, Monopolio, Seguridad, Defensa.

Clasificación JEL: D42, F52, H11, H42, H56 y H77.

Title: Molinarís Challenging Idea: A free and Competitive Defense System

Abstract: According to Gustave de Molinari (1819-1912) all monopoly is harmful to consumers because they receive worse goods and pay higher prices compared to what it would happen in the free market. We don't find either economic or logical reasons that justifies the state monopoly of the production of security and its existence should be explained by other means. Molinari's idea, which

* Formador en SOMER CONSULTING. Doctorando en Ciencias Sociales (Economía), Universidad Rey Juan Carlos. 
is no other than the laissez-faire doctrine driven to its ultimate consequences, is challenging because it implies de facto the dissolution of the State as we conceive it at present. The authorities will oppose, with all the means at their disposal, losing the coercive monopoly of production of security because it jeopardizes their interests, namely, power. There have been historical examples of non-State societies only in a small scale or in primitive and underdeveloped social groups. Perhaps, the only production of private security, in free competition, will be seen in the free cities projects or free cities under statute.

Keywords: Molinari, Laissez faire, Monopoly, Security, Defense.

JEL Classification: D42, F52, H11, H42, H56 y H77.

\section{I \\ INTRODUCCIÓN}

El artículo seminal que en 1849 escribiera Gustavo de Molinari titulado «La Producción de Seguridad» es probablemente la contribución más importante a la teoría moderna del anarcocapitalismo. Molinari sostiene una tesis simple y lógica, a la vez que desafiante para el pensamiento común: si todo monopolio es nocivo para los consumidores, el monopolio estatal de provisión pública de seguridad también lo es. En la literatura de economía política es difícil encontrar un artículo que sea a la vez tan breve (trece páginas) y tan fértil en ideas. En efecto, Molinari se muestra clarividente en muchos aspectos: expresa el carácter evolutivo de la sociedad y de las instituciones, alerta de los peligros del constructivismo social y explica cómo el Derecho (Ley descubierta) se transforma perversamente en legislación (Ley creada), claros antecedentes de la Teoría Evolutiva de las Instituciones (Martínez, 2013); denuncia los perjuicios que el intervencionismo ocasiona a los consumidores (Rothbard, 2013b); concibe el concepto austriaco de monopolio; vislumbra la naturaleza agresiva y expansiva de los estados (Higgs, 1987; Rummel, 1994) y desmonta el mito de que el socialismo, la democracia o la regla de la mayoría puedan lograr un orden social justo (Huerta de Soto, 2001).

La tesis de Molinari que ahora defendemos, a saber, que la producción privada de seguridad en libre competencia es económica- 
mente más ventajosa para los consumidores que la producción pública, posee sólidos cimientos teóricos. En general, todo monopolio es muy ventajoso para el productor ya que éste determina unilateralmente la cantidad producida, el precio y demás términos en los que se realiza el intercambio; obviamente, esto perjudica los intereses de los consumidores. «Monopolista» es un calificativo que implica abuso (Rothbard, 2013c: 171). Según Wayland (Rothbard, 2013c: 173) monopolio es el «derecho exclusivo otorgado a un hombre o a un conjunto particular de hombres para que utilicen su trabajo o capital de alguna manera especial»; si admitimos provisionalmente esta definición, el monopolio no tiene cabida en el libre mercado y sólo puede ser consecuencia, directa o indirecta, del intervencionismo gubernamental. Pero existen diferencias entre un monopolio privado y uno público: en el primero, aún a pesar de las ventajas otorgadas por el gobierno, el consumidor puede soslayar al monopolista de dos formas: a) reduciendo su consumo y b) eludiendo completamente el intercambio, ya sea consumiendo bienes sustitutivos o incluso absteniéndose por completo de consumir. En el monopolio público, las opciones de reducir o eludir el intercambio son prácticamente nulas ya que los consumidores se ven forzados legalmente a pagar y consumir determinados bienes. El ciudadano es expropiado igualmente, haga o no haga uso del servicio público. Es preciso aquí aclarar que en toda relación hegemónica y coactiva el concepto de «intercambio» pierde su significado. Todo intercambio stricto sensu requiere libertad y consentimiento de las partes que lo realizan. Todo monopolio (Chodorov, 2002: 60) es un negocio del tipo «lo tomas o lo dejas» pero cuando de monopolios públicos se trata, la fórmula se torna del tipo «lo tomas o lo tomas», por tanto, el monopolio público resulta más lesivo para las personas que el privado. Refiriéndonos al monopolio de la seguridad, el impuesto personal de la conscripción ${ }^{1}$ es particularmente agresivo con los ciudadanos si bien algunas legislaciones admiten la objeción de conciencia en esta materia. En cambio, no existe gobierno alguno que admita la objeción fiscal y tanto el ciudadano belicista como el pacifista deben pagar impuestos para financiar los servicios de defensa y, en su caso, la guerra. Por otro

1 Servicio militar obligatorio. 
lado, el monopolio estatal de la seguridad no permite al consumidor comparar el precio pagado con el servicio de protección recibido, entre otras cosas, porque el pago de impuestos es global e indiferenciado. El gobierno cobra impuestos mediante la confiscación de dinero por diferentes conceptos o «hechos imponibles» y luego compra material bélico o paga la nómina de los militares sin que podamos saber nuestra contribución ${ }^{2}$ económica a la defensa nacional o si el servicio recibido es caro o barato. Hacer invisible o difusa la conexión entre precio y servicio es primordial para el productor monopolístico porque así el consumidor no puede evaluar la utilidad del intercambio, metafóricamente está ciego en el sentido cataláctico y su perspicacia para advertir su beneficio o perjuicio queda muy reducida. En cambio, la conscripción, como impuesto que implica una prestación personal al Estado, permite al ciudadano ver nítidamente las condiciones en las que se realiza el intercambio, es decir, la utilidad o desutilidad en términos de coste de oportunidad que supone servir en filas. Este hecho hace del servicio militar obligatorio un impuesto impopular y por ello prácticamente ha desaparecido ${ }^{3}$ de la mayoría de las naciones democráticas ${ }^{4}$. La conscripción presenta otros problemas suplementarios como la discriminación por razón de sexo, edad o capacidad psicofísica para realizar la prestación personal lo que hace que aquél generalmente recaiga en jóvenes varones de clase social media y baja.

Existen muy pocas sociedades donde la seguridad no es producida por un monopolio público. Sin embargo, la provisión privada de seguridad no es una utopía, ha existido en el pasado y todavía existe en el presente. Tras 150 años de desarrollo del Estado-nación moderno, éste ha demostrado una gran capacidad para sostener el

\footnotetext{
${ }^{2}$ El término contribución aquí usado es equívoco pues «contribuir» implica una voluntariedad que no existe en el ámbito fiscal. La exacción no es voluntaria y, por tanto, sería más preciso llamar al «contribuyente» por su verdadero nombre: «expropiado».

3 «Desaparición» no es sinónimo de «abolición». Se trata de una suspensión temporal legislativa de la prestación mientras así lo permita las necesidades de la defensa nacional.

4 Algunas excepciones son Brasil, Corea del Sur, Filipinas, Grecia, Israel, Méjico, Noruega, Rusia, Singapur, Suiza, Turquía y Ucrania.
} 
monopolio público de la seguridad y extender su poder sobre otros sectores económicos de la sociedad. Todos aquellos que valoramos la sociedad abierta observamos con preocupación que el Estado no deja de aumentar en tamaño, presupuesto y funciones; y todo poder humano procura aumentar sus prerrogativas (Michels, 2003: 10). Entre 2007 y 2011 (Rallo, 2014: 10) todos los países del G-7 y los periféricos (Portugal, Irlanda, Grecia y España) han visto crecer sus Estados una media de 15\% y en todos los casos la participación del Estado en la economía supera el $40 \%$ del PIB. La abolición del monopolio estatal de la coacción constituiría una innovación social de dimensiones colosales pues supondría la aparición de órdenes sociales espontáneos de carácter anarquista, ya sean estos de corte colectivista o capitalista. Sin embargo, la defensa de la anarquía no es la defensa de una verdad definitivamente probada y no es posible garantizar que el nuevo orden social resultante sea más benigno que el orden estatalizado, habría que analizar caso por caso.

\section{II}

\section{LOS ARGUMENTOS DE MOLINARI}

La argumentación de Molinari comienza apelando al iusnaturalismo y al orden social espontáneo frente al constructivismo social que, para él, representa el Gobierno. La sociabilidad es una característica del ser humano que podemos atribuir (Mises, 2011: 192) a la acción humana estimulada por la mayor productividad del trabajo bajo la división del mismo. Pero vayamos a lo que más nos interesa. Molinari nos presenta este razonamiento lógico:

Premisa 1: «Que en todos los casos, y para todos los bienes que sirven para satisfacer las necesidades materiales o inmateriales del consumidor, el interés del consumidor consiste en que el trabajo y el intercambio permanezcan libres, porque la libertad de trabajo y de intercambio tienen como resultado necesario y permanente la máxima reducción del precio de las cosas».

Premisa 2: «Que el interés del consumidor de cualquier bien debe prevalecer siempre sobre el interés del productor.»

Conclusión: «Que la producción de la seguridad debe, por el interés de los consumidores de este bien inmaterial, permanecer 
sometido a la ley de la libre competencia. De donde resulta: Que ningún gobierno debe tener el derecho de impedir a otro gobierno entrar en competencia con él, o de obligar a los consumidores de seguridad a dirigirse exclusivamente a él para obtener este servicio.»

Esta argumentación, original por su osadía, mezcla dos elementos que pertenecen a campos epistemológicos diferentes. La primera premisa es descriptiva: todo monopolio tiende a producir bienes de peor calidad y a mayor coste que otro productor sometido a la competencia del mercado. Esta afirmación aspira a ser una ley económica y goza de amplísimo acuerdo. La segunda premisa, en cambio, introduce un elemento axiológico mediante el uso del término «debe». Y aquí no es posible alcanzar el acuerdo, al contrario, muchos piensan que el «interés general» — caso de que existiera- y representado por el Gobierno, debe prevalecer sobre el interés del consumidor individual. Por tanto, esta segunda premisa cae fuera del ámbito de la economía que como ciencia teórica se abstiene de establecer normas de conducta (Mises, 2011: 11). La conclusión de Molinari introduce una valoración problemática ya que, como hemos visto, siempre pueden encontrarse otros valores distintos o incluso razones sociológicas o históricas que justifiquen un monopolio gubernamental. Por ejemplo, la necesidad de la «seguridad colectiva» ${ }^{5}$ en caso de guerra ha sido históricamente situada por encima del interés de los individuos: la confiscación de bienes, el aumento de impuestos, el acantonamiento de tropas o la conscripción son algunos ejemplos de lo anterior.

Molinari no admite, intelectualmente, que una ley económica tenga excepciones y tacha a sus opositores de no ser economistas «puros». La producción de seguridad no debe ser una excepción pues las leyes económicas tienen la misma validez que las leyes naturales que rigen el mundo físico (como la gravitación universal). Ambos tipos de leyes deben cumplirse en todo momento, lugar y circunstancia. Quizá, esta equiparación epistemológica entre física y economía no esté adecuadamente justificada pues (Feito,

5 Está por ver si realmente existe algo tal como la «seguridad colectiva» pero usamos la expresión debido a su uso generalizado. 
2010: 113) apelar a un presunto orden natural es problemático cuando tratamos actos humanos. Además (Popper, 2010: 489), ni la naturaleza ni la historia pueden decirnos lo que debemos hacer.

El sostenimiento sin fisuras ni concesiones de sus propias conclusiones lógicas es, sin duda, una de las aportaciones más importantes de Molinari a un tipo de razonamiento económico radical que también observamos en otros autores anarquistas coetáneos como Spooner y Thoreau, y también posteriores como, Rothbard, Hoppe, Higgs, Block, Friedman, Huerta de Soto y Bastos; entre otros. Y utilizamos aquí el término «radical» no en sentido peyorativo sino como muestra de integridad intelectual. Molinari llega a su conclusión mediante un razonamiento lógico-deductivo, no empírico, pudiendo ser considerado precursor del método epistemológico usado por la Escuela Austriaca de Economía. La exigencia de que la producción de seguridad, como en cualquier otro bien económico, se realice en régimen de libre competencia no es sólo una reclamación más de la doctrina económica del laissez faire sino que, colateralmente, supone un ataque frontal a la propia existencia del Estado, cuya esencial función histórica ha sido ejercer el monopolio de la fuerza institucionalizada.

\section{III \\ ARGUMENTOS EN FAVOR DEL MONOPOLIO ESTATAL Y SUS CRÍTICAS}

Cualquier estudioso de la Escuela Austriaca de Economía que pretenda alinearse con la defensa del libre mercado en todas sus facetas se enfrenta ineludiblemente a la espinosa cuestión de refutar a dos de sus grandes maestros: Mises y Hayek. El primero (Mises, 2011: 180) defendió al Estado como productor monopolístico de seguridad:

El estado o gobierno es el aparato social de compulsión y coerción. Debe monopolizar la acción violenta. Ningún individuo puede recurrir a la violencia o a la amenaza de emplearla si no ha sido autorizado por ello por el gobierno. El estado es una institución cuya función esencial estriba en proteger las relaciones pacíficas entre los hombres. 
Para el profesor Benegas Lynch (Mises, 1959: VIII), «las ideas de von Mises sobre la libertad y la función del gobierno ponen bien claro que el gobierno es una de las instituciones humanas más beneficiosas cuando cumple su cometido», pero debemos apostillar que esto último no es tan obvio. De hecho (Popper, 2010: 482), «la historia del poder político no es sino la historia de la delincuencia internacional y del asesinato en masa». Y puesto que los derechos del individuo no constituye un límite a la acción gubernamental, debemos cuestionar prima facie la postura misiana. Él mismo afirmaba en 1922 (Mises, 1959: 31): «la economía exige la paz y la exclusión de cualquier tipo de violencia» pero tal vez excluyera de esta afirmación la violencia institucional ejercida por el Estado.

Todos los argumentos que justifican el monopolio estatal de la seguridad pueden ser criticados, al menos, desde los siguientes puntos de vista:

\section{Ontológico}

Es frecuente considerar al Estado (y al Gobierno) como un ser con existencia propia y diferente de los individuos que lo componen, este «ser» nocional goza de un estatus superior al de las personas físicas. El Estado es como un padre (Samuelson, 2005: 35), su autoridad, ecuanimidad y bondad garantizan supuestamente un empleo adecuado y justo de la fuerza que ejerce a través de instituciones legitimadas por los gobernados. Este es el concepto idealizado del «dictador benevolente» ${ }^{6}$. Otras analogías contemplan al Estado como un médico que sana a la sociedad (Samuelson, 2005: 34): «en todos los casos, las fallas de mercado provocan producción o consumo ineficientes y el Estado puede contribuir significativamente a curar la enfermedad». La tesis ontológica del ser superior, paternal y bondadoso se refuta desde el individualismo metodológico. Frédéric Bastiat irónicamente describe el Estado (Bastiat, 1948: 1) así: «Todo lo que nosotros sabemos es que es un personaje misterioso, y seguramente el más solicitado, el más atormentado, el más

${ }^{6}$ Krause, 2012, conferencia Instituto Juan de Mariana.

https://www.youtube.com/watch?t=273\&v=v_4m3WvwC8Y 
atareado, el más aconsejado, el más acusado, el más invocado y el más provocado que hay en el mundo. Porque, Señor, no he tenido el honor de conocerle». Y el profesor Bastos niega categóricamente su existencia ontológica (Bastos, 2005: 15): «El Estado como tal no existe, son personas organizadas y jerarquizadas, vinculadas por relaciones jurídicas y de poder, que operan sobre un territorio monopolizando el uso de la fuerza».

\section{Biológico}

Otra justificación del monopolio de la fuerza se basa en considerar que existen diferencias en la naturaleza de los hombres. Para sus defensores, existen hombres «privados» egoístas que persiguen su propio interés y hombres «públicos» altruistas que persiguen el interés general. Los primeros, tal vez debido a sus imperfecciones, no deben recurrir a la violencia pero un hombre genial o divino - el Soberano- o un grupo de hombres «especiales» - políticos y funcionarios- sí pueden legítimamente hacerlo. Su antecedente es el famoso Leviatán de Hobbes (1651) que atribuye a los hombres una naturaleza feroz y agresiva; Lupus est homo homini ${ }^{7}$, excepto el Soberano, que está dotado naturalmente o ungido sobrenaturalmente y que posee una naturaleza menos agresiva que el resto de sus congéneres. Hoppe refuta la tesis hobbesiana de una forma tan sarcástica como efectiva: como el hombre es un lobo para el hombre, pongamos a un «Gran Lobo» al mando. Por otro lado, la metáfora de Hobbes, aun comprendiendo su significado, carece de validez argumental porque la especie «lobo» - ni ninguna otra- puede ser considerada como bondadosa o malvada. La biología no puede servirnos para alcanzar conclusiones axiológicas pues los animales, al contrario que los hombres, se comportan de una forma puramente instintiva; así pues, carece de sentido afirmar que lobos y tiburones son «malos» o que ciervos y delfines son «buenos». Por otro lado, de la especie homo sapiens tampoco podemos afirmar que sea mala o buena en general pues los juicios de valor sobre la conducta humana sólo son aplicables a individuos particulares y a sus conductas específicas.

\footnotetext{
7 «Lobo es el hombre para el hombre».
} 


\section{Monopolio natural}

Este argumento puede considerarse un caso particular del anterior. En un mercado libre de la seguridad sería posible que un único proveedor se erigiera de forma natural en monopolista del servicio y, una vez alcanzada la posición hegemónica, utilizara indebidamente su fuerza para someter coactivamente a sus clientes. Pero algunos no parecen darse cuenta de que este escenario indeseado ya lo tenemos en la actualidad y ese monopolista se llama «gobierno». La tesis del monopolio natural presupone que un monopolio dirigido por empresarios ávidos de poder sería más dañino que otro dirigido por políticos igualmente ávidos de poder. Sin embargo, no encontramos razones para suponer que los empresarios superen en avidez y malignidad a los políticos ni que un monopolio privado pueda resultar más dañino que uno público. Tal vez sucede lo contrario (Benson, 2000: 336) pues el empresario (no mercantilista) triunfa gracias a su mayor capacidad para satisfacer eficazmente las necesidades de sus clientes mientras que el político triunfa por su especial habilidad para alcanzar el poder y ejercer la coacción sistemática sobre terceros. En cualquier caso, no es probable que el libre mercado conduzca a un único proveedor de seguridad, y habiendo muchos, cualquier intento de abuso de poder por parte de alguno de ellos sería eventualmente contrarrestado por el resto.

\section{Teleológico-Lógico}

Los mercados solo funcionan si se respetan los derechos de propiedad (Mankiw, 2007: 8) y el monopolio público es el garante de lo anterior. Pero resulta contradictorio (Hoppe, 2004: 130) que la misma agencia encargada de proteger la propiedad sea la primera es violarla mediante la confiscación fiscal. Los que apoyan la tesis de la condición sine qua non (Rothbard, 2013b: $372^{8}$ ) del monopolio de la fuerza se ven atrapados en una contradicción insoluble, pues propugnan y defienden una intromisión masiva en la propiedad mediante el mismo agente - el gobierno - que se supone defiende a la gente de di-

${ }^{8}$ La edición Kindle no expresa páginas sino «posición» 372 de 6.526. 
cha amenaza. Praxeológicamente hablando, un gobierno y una mafia actúan de idéntica manera, ambos son entes protectores-agresores que establecen un vínculo hegemónico (Mises, 2011: 234) con sus «protegidos» y donde el proveedor del servicio determina unilateralmente los términos de la relación sin que el cliente sea libre de rechazar el intercambio. El Estado, por lógica — afirma Molinari- debe recurrir forzosamente al empleo de la violencia: «Dado que la autoridad moral de los gobernantes no se apoya, en realidad, más que en el propio interés de los gobernados, y dada la tendencia natural de éstos a resistir a todo lo que dañe su interés, hará falta que la autoridad no-reconocida recurra incesantemente a la fuerza física».

\section{Teleológico-Histórico}

La finalidad esencial del Estado es proteger la vida y propiedad privada de los individuos frente a las agresiones de otros individuos, grupos o Estados. Pero históricamente no es tan evidente que los diferentes gobiernos hayan cumplido cabalmente su misión protectora. Todos los gobiernos, totalitarios y democráticos, presentan un tenebroso historial de víctimas causadas a sus propios ciudadanos. No es infrecuente que el gobierno utilice el monopolio de la fuerza en su propio interés reprimiendo y masacrando a la población. Tan sólo en el siglo XX se contabiliza, excluyendo las guerras, 169.202.000 muertos causados directa o indirectamente por los Estados, cifra terrorífica de algo que Rummel denomina «democidio» o asesinato masivo. Los principales gobiernos criminales (Rummel, 1994: 390) han sido9: USSR: 61,911; China (República Popular): 35,236; Alemania: 20,946; China (Kuomintang): 10,075; Japón: 5,964; China (Mao): 3,466; Camboya: 2,035; Turquía: 1,883; Vietnam: 1,687; etc.

\section{Antropológico}

El monopolio de la coacción es el requisito previo para que la sociedad, en general, y el mercado, en particular, puedan existir. Afir-

\footnotetext{
9 Millones de muertos.
} 
ma Mankiw (2007: 8): «Una de las razones por las que necesitamos el Estado es que la mano invisible solo puede hacer su magia si el Estado vela por el cumplimiento de las normas y mantiene las instituciones que son clave para una economía de mercado». Sin una autoridad coercitiva - afirman algunos— no es posible garantizar la cooperación social, el intercambio o la libre competencia en ninguna otra área de la acción humana. La tesis «antropológica» u «originaria», que entiende la existencia del Estado como condición sine qua non para la existencia del orden social podemos criticarla de dos formas: a) Las primeras sociedades humanas son anteriores a cualquier forma de organización más compleja como es el Estado. La existencia de una élite política, religiosa o militar, que no participa en la producción, supone forzosamente la existencia de excedentes alimentarios y de otro tipo de bienes. A su vez, esto implica algún tipo de colaboración social bajo el signo de la división del trabajo. Necesariamente, todo poder organizado fue posible gracias a la cooperación humana. b) Todas las relaciones internacionales se producen en régimen de anarquía, es decir, en ausencia de un gobierno mundial común a todas las naciones. Fruto de esta libre cooperación es la aparición de instituciones evolutivas como el dinero o el comercio. Por ejemplo, la Lex Mercatoria Internacional fue el instrumento de regulación de las relaciones privadas internacionales antes que el Derecho Mercantil hiciera su aparición en la Edad Media (Tovar, 2004: 158). Actualmente, la mayoría de conflictos mercantiles transnacionales son resueltos mediante árbitros privados internacionales no sometidos a las legislaciones estatales. Para Rothbard (2013b: 393): «las fronteras actuales de las naciones son lisa y llanamente históricas y arbitrarias y no hay más necesidad de un monopolio gubernamental sobre los ciudadanos de un país de la que hay para uno entre ciudadanos de dos naciones distintas»

\section{Marginalista}

Afirman los estatistas que la seguridad, al igual que la justicia y otros servicios públicos vitales, es una necesidad tan primordial para la sociedad que su provisión debe quedar enteramente en ma- 
nos del Estado. Menger y Böhm-Bawerk usaron el término «clases de necesidades» para refutar la supuesta paradoja del valor. Los consumidores nunca optan entre «clases» de bienes, no eligen entre alimentarse o protegerse, en todo caso deben elegir entre comprar un kilo de tomates o comprar un candado. Todas las acciones humanas son referidas a cantidades discretas de bienes según las escalas personales de valores, es decir, según la ley de la utilidad marginal. En este sentido (Mises, 2011: 148) «a nada conduce agrupar las diversas necesidades en clases para después concluir que tal ordenación carece de interés en el terreno de la teoría del valor». La economía moderna demuestra que los servicios deben considerarse en términos de unidades marginales (Rothbard, 2013b: 382). La teoría maslowiana de la motivación humana, que establece una jerarquía de «clases» de necesidades ${ }^{10}$ adolece del mismo error. Tratándose del bienestar humano, el primer lugar no lo ocuparía la seguridad sino la alimentación, la vivienda o el vestido (BöhmBawerk, 1998: 251). Por otro lado, del hecho de que algo sea reconocido como importante para el común de las personas no se infiere que deba ser el Estado su productor exclusivo, más bien al contrario, cuanto más importante sea un bien para el consumidor mayor interés tendrá éste en que su producción se realice bajo un régimen de libre competencia.

\section{Funcional-institucional o minarquista}

Algunos autores defienden el monopolio estatal de la fuerza basándose en la existencia funciones «esenciales» para la sociedad, que mínimamente e imperativamente deben estar a cargo exclusivo del Estado con objeto de mantener el orden social. Mises y Hayek, entre otros muchos liberales, mantienen esta posición que constituye, por así decirlo, el paradigma minarquista o del Estado mínimo. Si se afirma que existen funciones sociales «esenciales» para la sociedad — seguridad, defensa y justicia - que deben ser realizadas por sendas instituciones públicas - Fuerzas y Cuerpos de Seguridad del Estado, Fuerzas Armadas y Poder Judicial- debemos inferir nece-

10 Básicas, de seguridad y protección, sociales, de estima y autorrealización. 
sariamente que existen otras funciones e instituciones «no esenciales» $\mathrm{o}$ «menos esenciales» para la sociedad y que pueden funcionar en el libre mercado. Esta apelación a una supuesta «esencialidad» funcional e institucional, a nuestro juicio, es problemática y nos conduce a una disputa irresoluble. En primer lugar, la categorización sobre qué función es esencial o no esencial es un juicio de valor, y el valor es subjetivo, alguien podría afirmar que la familia, el lenguaje, el dinero, la propiedad privada o la religión son instituciones tanto o más «esenciales» que la Policía, el Ejército o la Justicia. Para un pacifista, por ejemplo, la necesidad de defensa no es esencial en absoluto. La tesis de la «esencialidad» de las funciones e instituciones —entendida como «clases»— presenta un asombroso parecido con la tesis de las «clases de bienes» y la crítica misiana de este concepto, mutatis mutandi, es aplicable al intento de establecer clases de funciones e instituciones. Si la seguridad es un bien económico que no puede legítimamente categorizarse como clase, tampoco parece adecuado categorizar las instituciones que proveen dicha seguridad. No tiene mucho sentido afirmar que el Estado debe monopolizar la producción de fusiles, cañones o aviones de combate porque es «esencial» para la sociedad pero que no debe monopolizar la producción de agua, alimentos, vestido o vivienda porque son (supuestamente) «no esenciales» $\mathrm{O}$ «menos esenciales» para la sociedad. Mises parece no advertir que tan vano es pretender establecer «clases» de bienes económicos como «clases» de funciones o «clases» de instituciones. Las instituciones son entes complejos, fruto de dilatados procesos evolutivos (Martínez, 2013: $4701^{11}$ ) y no creemos que sea posible establecer con carácter general una ordenación jerarquizada y objetiva según clases. Cualquier intento de ordenación objetiva de carácter axiológico es necesariamente arbitraria y problemática pues viola los principios de subjetivismo y marginalismo sobre los que se sustenta la ciencia económica. Sin embargo, no cabe la menor duda de que para aquellos - políticos y funcionarios- que forman las filas del aparato estatal mantener el monopolio de la fuerza es esencial para su propia supervivencia y statu quo. La fuerza física es la más esencial de todas las funciones gubernamentales porque sin ella no sería posi-

11 Posición del texto en la edición kindle. 
ble el resto de monopolios públicos: confiscación, dinero, producción de leyes, justicia y, en general, la toma última de decisiones sobre los habitantes de un territorio dado.

Por último, existen otros «no argumentos» que eluden la racionalidad argumentativa para entrar directamente en el campo de las descalificaciones y las falacias ad hominem. El colega de Molinari y libertario francés Charles Dunoyer, denominó su propuesta (Rothbard 2013: 1061) como «ilusiones de la lógica». Según Dunoyer, la competencia en la producción de seguridad es quimérica y, como alternativa, propone la competencia entre partidos políticos dentro del sistema representativo. Si damos por válida la tesis de Dunoyer llegaríamos al absurdo de admitir que la simple alternancia democrática en el poder elimina mágicamente la situación de monopolio. Pero aquella no elimina el monopolio, tan sólo lo cambia transitoriamente de manos. La producción de seguridad al margen del Estado supone un atentado frontal al paradigma social existente (Kuhn, 2003: 63) y, sin duda, cualquier propuesta en este sentido tendrá difícil aceptación y será vista por muchos como heterodoxa, utópica (Negro, 2014) o incluso extravagante y cosa de locos (Bastos, 2014) ${ }^{12}$.

IV

\section{EL ARGUMENTO DE LOS BIENES PÚBLICOS}

Hemos querido dejar en último lugar el argumento de los bienes públicos por ser el paradigma económico dominante que justifica el monopolio gubernamental de la seguridad.

\section{Bienes públicos}

Bien público es aquél (Samuelson, 2005: 35) «que todos pueden disfrutar y que es imposible impedir que alguien los disfrute». Dicho

12 El profesor Dalmacio Negro habla por sí mismo mientras que el profesor Miguel Anxo Bastos se refiere a la opinión del común de las personas. Ambas citas proceden de conferencias impartidas en el Instituto Juan de Mariana. 
de forma más técnica, son bienes cuyo consumo satisface dos criterios: a) no exclusividad: no es posible excluir a nadie del consumo de ese determinado bien, por ejemplo, no podemos impedir que un peatón o un vehículo circulen por la vía pública; b) no rivalidad: el consumo del bien por un individuo no excluye ni reduce el consumo de ese mismo bien por parte de otros consumidores adicionales. El aumento marginal del número de consumidores no aumenta el coste marginal de producción del bien en cuestión, o dicho de otro modo, para el productor el coste marginal de añadir un consumidor más es cero.

\section{Bienes privados}

Todos los bienes económicos ${ }^{13}$ de naturaleza física son privados porque existe la posibilidad de excluir del consumo a aquellos que no quieren o no pueden pagar por su adquisición ${ }^{14} \mathrm{y}$, de otra parte, existe rivalidad en su consumo. Si una persona ingiere un vaso de leche, ese mismo alimento no puede ser ingerido por otra persona. Es preciso advertir que la teoría de los bienes públicos soslaya satisfactoriamente la problemática cuestión de la «esencialidad» de los bienes. La defensa nacional, por tanto, debe ser producida públicamente no porque sea más (o menos) «esencial» que los alimentos sino por razones de excluibilidad y rivalidad. Los alimentos son bienes privados, cuya producción es dejada al libre mercado, porque en su consumo se responde afirmativamente a las cuestiones de exclusión y rivalidad.

\section{Recursos comunes}

Hay rivalidad en el consumo pero no es posible excluir a nadie. Las externalidades negativas generadas requiere la intervención gubernamental. El caso de las calles es paradigmático: existe una gran ri-

13 Un bien no escaso, como el aire o el agua del océano, no es un bien económico.

${ }^{14}$ Una de las funciones del sistema de precios es asignar los bienes a los compradores. La otra es orientar a los empresarios sobre qué bienes deben ser producidos y cuáles no. 
validad por encontrar aparcamiento pero no es posible excluir a los conductores. Sin embargo, las propias autoridades han ideado fórmulas de exclusión como las tarjetas de aparcamiento para discapacitados o residentes, las zonas de carga y descarga, la limitación del tiempo de aparcamiento o el uso por pago (parquímetros). Otras medidas, como que los vehículos con matrículas pares (o impares) circulen por la ciudad en días alternos no suelen ser efectivas por su carácter arbitrario. La intervención gubernamental, por otro lado, agrava el problema por el lado de la oferta limitando el espacio disponible (la ordenación urbanística puede dificultar la construcción de aparcamientos privados) o prohibiendo el uso compartido del taxi, las moto-taxi o el trabajo de taxistas ocasionales (Uber).

\section{Monopolio natural}

Es posible excluir al consumidor que no paga por el servicio pero los productores, una vez hechas las infraestructuras básicas, pueden abastecer a consumidores adicionales con un aumento despreciable de los costes de producción. Las empresas que suministran agua y energía constituyen ejemplos de lo anterior.

En el cuadro inferior se reflejan algunos ejemplos de los cuatro tipos de bienes según los criterios de excluibilidad y rivalidad.

FIGURA 1

LAS CUATRO CLASES DE BIENES SEGÚN MANKIW (2007: 158)

\begin{tabular}{|c|c|c|c|}
\hline & & ¿Rir & onsumo? \\
\hline & & Si & No \\
\hline$\frac{\stackrel{0}{0}}{\stackrel{\Xi}{\Xi}}$ & Si & $\begin{array}{l}\text { Bienes privados: } \\
\text { - Alimentos. } \\
\text { - Ropa. } \\
\text { - Autopista de peaje. }\end{array}$ & $\begin{array}{l}\text { Monopolios naturales: } \\
\text { - Bomberos públicos. } \\
\text { - TV por cable. } \\
\text { - Cía. Eléctrica, agua, gas. }\end{array}$ \\
\hline$\sim$ & No & $\begin{array}{l}\text { Recursos comunes: } \\
\text { - Pesca extractiva. } \\
\text { - Medio ambiente. } \\
\text { - Carreteras públicas. }\end{array}$ & $\begin{array}{l}\text { Bienes públicos: } \\
\text { — Defensa nacional. } \\
\text { — Sirena para tornados. } \\
\text { — Faro marítimo. }\end{array}$ \\
\hline
\end{tabular}


Según la noción pigouviana-samuelsoniana la defensa nacional es un bien público porque, en ausencia de impuestos que la financiara, unos consumidores costearían voluntariamente el servicio mientras que el resto - free-riders o gorrones- se beneficiaría igualmente (criterio de no excluibilidad); por otro lado, una vez constituido el servicio de defensa nacional, el incremento de ciudadanos adicionales dentro del territorio no incrementa el gasto militar (criterio de no rivalidad). En conclusión, si no fuera por la intervención pública, la producción de defensa en un sistema laissez faire, sería insuficiente, de pobre calidad o sencillamente no existiría en absoluto. Por ejemplo, la nación A tiene un censo de cinco millones de habitantes y suponemos que prácticamente la totalidad opina que la defensa es una necesidad. El presupuesto gubernamental para la defensa de A es 1.000 millones de euros (1\% PIB) al año, lo cual supone un gasto de $200 €$ por habitante y año. Si dejáramos la defensa nacional en manos del mercado sería previsible que muchos ciudadanos no contratasen las pólizas de seguro, esperando beneficiarse del servicio pagado por los demás; al fin y al cabo las Fuerzas Armadas que defienden un territorio extenso no pueden distinguir entre los que sufragan el servicio y los free-riders. Probablemente, mediante el pago voluntario del servicio, el dinero disponible no cubriría ni remotamente las necesidades del conjunto de la defensa y la «infraproducción» del servicio aumentaría considerablemente el riesgo de ser atacado por otro Estado. Este razonamiento, que ilustra la teoría de los «fallos del mercado», justifica el cobro de impuestos para sufragar el servicio y aumentar así la utilidad social.

\section{Sobre los criterios de no excluibilidad y no rivalidad}

No existe una clara dicotomía entre bienes públicos y privados (Hoppe, 2013: 3920). Intentaremos demostrar, utilizando la propia teoría de los bienes públicos, que la seguridad puede ser catalogada como un bien privado. En primer lugar, la seguridad es un bien escaso. Las fuerzas militares (y policiales) siempre son limitadas y una de las principales decisiones estratégicas del Mando militar es dónde y cuándo deben ser empleadas. Una vez comprometidas en combate, es muy difícil reasignar las fuerzas $y$, de hacerlo, su coste es muy 
elevado. La máxima militar de mantener unidades en reserva, a pesar de la precariedad de medios, se deriva de las necesidades de la incertidumbre en la guerra y de mantener la libertad de acción. Idéntico problema, pero a otro nivel, plantea en la intervención de unidades policiales o de protección civil (bomberos). Si una patrulla de policía acude a una emergencia no estará disponible para dar servicio a otra emergencia que suceda al mismo tiempo y en otro lugar. Por tanto, la rivalidad en el consumo de seguridad existe forzosamente en cualquier circunstancia. Si una división mecanizada defiende una zona vital de la frontera de un país dejará sin cubrir otra zona que no es vital para el país. Durante la guerra, los ciudadanos sufren sus consecuencias de forma desigual sin que sea posible defender a todos de manera uniforme. Una fragata que patrulla en el océano Indico — solución ofrecida por los gobiernos contra la piratería en el Cuerno de África- sólo puede proteger a un reducido número de buques civiles ${ }^{15}$ (cargueros, petroleros, atuneros); creemos que esta forma de producción de seguridad es inadecuada ya que unos pocos barcos quedan sobreprotegidos (por la fragata) mientras que la inmensa mayoría quedará inerme en una vasta zona marítima equivalente a 1,5 veces el tamaño de Europa. Ante la escasez de la oferta, no podemos descartar la búsqueda de privilegios y favores (lobbies) para que los militares protejan a unos buques a expensas de otros. En cambio, el mercado puede resolver de forma eficiente las necesidades de seguridad específicas de armadores y tripulaciones mediante la protección individual de cada buque. Una solución es armar y entrenar militarmente a las tripulaciones, otra es la contratación de seguridad privada: equipos —entre dos y cuatro agentes- de protección que se asignan a cada buque; la tercera, la constitución de convoyes marítimos que sufragan conjuntamente su seguridad. Todas las formas anteriores, además, pueden combinarse ad hoc quedando oferta y demanda satisfechas; cada cliente contrata la seguridad que considera según sus necesidades específicas y su criterio empresarial. La seguridad privada soslaya los su-

15 En la Operación Atalanta de EU Navfor (Fuerzas Navales de la Unión Europea), la zona marítima de operaciones en el océano Índico abarca 3,7 millones de $\mathrm{Km}^{2}$, extensión equivalente a 1,5 veces Europa. Para esta vasta zona, el promedio de buques de guerra desplegados, entre 2009 y 2013, es siete. Fuente: http://eunavfor.eu/ 
puestos problemas de no excluibilidad y no rivalidad que finalmente no resultan ser tales. Por tanto, la distinción entre bien público y bien privado no es tan clara como afirma la teoría de los bienes públicos. Además, todos los bienes que hoy consideramos públicos (sanidad, educación, asistencia social, transporte, etc.) han sido provistos de forma privada en el pasado, incluida la seguridad y la justicia. El argumento de los bienes públicos y su corolario, el monopolio estatal, imposibilita dar expresión a la demanda de seguridad por parte de los consumidores y ésta es sustituida por las decisiones del órgano de planificación central (Gobierno, Ministerios de Defensa e Interior). De esta manera, las preferencias de los individuos quedan sustituidas por las de políticos y funcionarios. Algunos gobiernos decidirán no poseer fuerzas armadas ${ }^{16}$, otros tendrán ejércitos de tamaño intermedio y otros realizarán gastos desmedidos que llevarán a la nación a la ruina. El aumento desmedido de los gastos de defensa y seguridad que dicta el gobernante discrecionalmente puede conducir al país a la ruina económica. La guerra y su preparación consumen recursos (Kennedy, 1989: 654) que las sociedades podrían utilizar para otras «empresas» sean públicas o privadas. Durante la Guerra Fría, el gasto militar de la extinta URSS era equivalente al $20 \%$ de su PIB. En 2004, el gobierno federal de EEUU gastó 456.000 millones de dólares en defensa nacional, alrededor de 1.500 \$ per cápita (Mankiw, 2007: 160) pero de aquí no se deduce, en modo alguno, que este gasto en defensa esté al servicio de los consumidores porque sólo a través de maximizar el beneficio monetario se logra que los factores se pongan a su servicio (Rothbard, 2013c: 148). Resulta paradójico que siendo EEUU la potencia militar hegemónica sus nacionales sean los más amenazados y que disfrutan de menos seguridad que los de Costa Rica o Panamá, naciones que no poseen fuerzas armadas. Si todos los ciudadanos de una nación financian con sus impuestos la agresión militar de su gobierno, incluso si se oponen a ella, son percibidos por las víctimas como colaboradores necesarios de aquella (Hoppe 2004: 332).

16 Barbados, Dominica, Granada, Haití, Islandia, Kiribati, Islas Marshall, Isla Mauricio, Micronesia, Nauru, Palaos, Panamá, Islas Salomón, Samoa, San Cristóbal y Nieves, Santa Lucía, San Vicente y las Granadinas, Tuvalu y Vanuatu, Andorra, Liechtenstein, Mónaco, San Marino y Ciudad del Vaticano. 


\section{6. ¿Es el free-rider realmente un problema?}

La teoría de los bienes públicos afirma que la existencia de externalidades positivas haría que determinados servicios en el libre mercado se produjeran de manera «insuficiente» en cantidad y/o calidad, o que dejaran de producirse. Sin embargo, una mera observación de la realidad cotidiana puede cuestionar la, a nuestro juicio, magnificada importancia que otorga la teoría samuelsoniana al free-rider. En primer lugar, no conocemos un solo caso en que la existencia de externalidades positivas sea un obstáculo para la producción bienes económicos. La construcción de sendas, veredas, caminos, puentes, plazas e iglesias, en tiempos no muy lejanos, era realizada o financiada privadamente por los habitantes del territorio sin importarles que otras personas disfrutaran de esas infraestructuras. Hoy en día, durante la celebración de las fiestas patronales de muchos pueblos en España, los vecinos - a nivel pueblo, barrio e incluso calle ${ }^{17}$ sufragan eventos tales como fuegos artificiales, banda de música, banda de cornetas y tambores, ornamentaciones florales, actuaciones musicales, etc.; en algunos sitios son las empresas locales las que corren con los gastos y en otros la financiación es mixta: privada y pública. Cada vecino aporta lo que quiere y puede sin que exista hostilidad hacia los que pagan menos o no han pagado nada. El free-rider no es considerado un problema. Por otro lado, la organización municipal del evento mediante el cobro de impuestos tampoco soslaya el presunto problema del free-rider pues entre los consumidores se hallan necesariamente visitantes y turistas que no pagan impuestos en la plaza. Pero podemos ir más allá y afirmar que no existe actividad humana que esté exenta de algún tipo de externalidad positiva o negativa. Si unos conductores pagan la autopista de peaje otros conductores se benefician gratuitamente de un tráfico menos congestionado en las carreteras públicas. Cuando alguien compra una plaza de garaje o paga parking otros conductores disponen de más espacio para aparcar en la vía pública. Y los que pagan sanidad y educación privadas descongestionan los hospitales y colegios públicos. La única persona ajena a

17 Esto viene sucediendo hace decenios en Santa Cruz de La Palma y en otras ciudades de Canarias. 
las externalidades sería un Robinson Crusoe sólo en su isla. El trabajo infatigable de algunos padres para proporcionar una sólida educación a sus hijos es una clara externalidad positiva que disfruta el resto de la sociedad; y la negligencia de otros progenitores provoca el efecto contrario. El comprador de un perfume no tiene en cuenta si las demás personas disfrutan gratuitamente de su aroma. Por otro lado, tampoco podemos estar completamente seguros si una externalidad es positiva o negativa porque el valor es subjetivo: un mismo olor puede ser agradable o desagradable según para quién. Tampoco hay forma de hacer un balance de las externalidades porque es imposible computar el pago y consumo de los servicios públicos. Un caso cotidiano se observa cuando una persona reside en un municipio pero trabaja en otro, según el punto de vista que elijamos, la externalidad puede ser considerada positiva o negativa. El Gobierno español considera free-riders a quienes trabajan en Gibraltar pero residen en Algeciras porque disfrutan de los servicios públicos españoles mientras que su impuesto sobre la renta se queda en el Peñón. Pero el alcalde de Algeciras (al igual que otros municipios «dormitorio») percibe a esas mismas personas como cuasi turistas que pagan impuestos ${ }^{18}$ y tasas $^{19}$ municipales, y realizan gran parte de sus compras dentro del municipio. Las mismas personas pueden ser consideradas simultáneamente como causantes de externalidades positivas y negativas.

En segundo lugar, que el gobierno no pueda excluir a los que no pagan por un servicio no significa que el mercado no pueda hacerlo. El mercado es eficiente encontrando soluciones tecnológicas ante cada problema. La TV en abierto era un bien público hasta que la invención de un decodificador de señal la convirtió en bien privado. Pero aunque no fuera posible excluir a los consumidores que no pagan por el servicio - caso de la radio o TV en abierto- existen soluciones de mercado como es la financiación del servicio mediante el pago por publicidad.

En conclusión, las externalidades positivas no constituyen un problema reseñable para la sociedad. De hecho, todo el progreso humano no es sino una acumulación histórica de externalidades

\footnotetext{
18 Impuesto de bienes inmuebles y circulación de vehículos.

19 Tasa de residuos sólidos, vado, etc.
} 
positivas donde cada generación disfruta de los logros conseguidos por todas las anteriores. No nos parece plausible que, en el caso de la seguridad, los consumidores súbitamente cambien su comportamiento y decidan permanecer inermes por la existencia de free-riders. Si los consumidores asumen habitualmente la existencia de externalidades positivas con mayor razón lo harán en el caso de bienes vitales. La seguridad, por tanto, será producida y consumida según la ley de la utilidad marginal independientemente de la mayor o menor existencia de free-riders. Los que afirman que sin el concurso de la coacción ningún consumidor estaría dispuesto a contratar seguridad privada deberán explicar por qué razón esos mismos consumidores mantienen voluntariamente la Wikipedia (y otras muchas organizaciones) donde los free-riders se cuentan por cientos de millones. A nuestro juicio, la teoría de los bienes públicos magnifica injustamente la importancia del free-rider en la economía y sus defensores presentan una visión apocalíptica y hobbesiana del libre mercado de la seguridad.

\section{Crítica de algunas conclusiones de la teoría de los bienes públicos}

En la teoría de los bienes públicos encontramos conclusiones que no están debidamente justificadas. Por ejemplo, se afirma que el libre mercado produciría cierto tipo de bienes - como la defensa- de forma «insuficiente». En primer lugar, lo que es «insuficiente» para el economista o para el gobernante tal vez sea «demasiado» para los consumidores. En el libre mercado las preferencias de cada consumidor se manifiestan individualmente de modo que la producción siempre es suficiente, o mejor dicho, tiende continuamente a ser suficiente porque la oferta se ajusta dinámicamente a la demanda. Afirmar que algo se produce de forma «insuficiente» es una ilegítima pretensión de conocimiento pues (Huerta de Soto, 2010: 158) «ningún ser humano o grupo de seres humanos puede disponer de la información o el conocimiento que es necesario o preciso para organizar coordinadamente la sociedad mediante mandatos coactivos». Dicha información es tácita, subjetiva, privativa, no articulable y se encuentra dispersa en las mentes de los consumidores. No es 
preciso repetir el razonamiento para refutar la supuesta «menor calidad» de los bienes producidos en el libre mercado. En segundo lugar, creemos igualmente ilegítima la afirmación de que mediante la producción gubernamental de bienes públicos se aumenta el beneficio social. Afirmar que la utilidad total o colectiva - caso de existir - aumenta cuando el Estado provee el servicio (Böhm-Bawerk, 1998: 239) pasa por alto varias cuestiones: a) la utilidad es subjetiva y no existe una unidad de medida; b) la utilidad es marginal y sólo puede referirse a cantidades discretas de bienes; y c) no es posible hacer comparaciones intersubjetivas de utilidad. Por tanto, el concepto de utilidad total o social carece de sentido (Mises, 2011: 147). Volvamos al ejemplo de los fuegos artificiales y expongamos nuestro razonamiento económico: a) si los vecinos gastan «insuficiente» cantidad de dinero o deciden no gastarlo en absoluto es síntoma de que poseen otras necesidades que deben ser cubiertas con mayor urgencia. Si el gobernante decide confiscar a los ciudadanos para costear entre todos la pirotecnia les está privando de alcanzar sus legítimos fines $y$, por tanto, se reduce la utilidad $\operatorname{social}^{20}$. b) Aún a pesar de la belleza que supone un espectáculo de fuegos artificiales, algunos vecinos pueden considerarlo una desutilidad, por ejemplo, a los dueños de perros y gatos no les gusta ver cómo sus mascotas sufren de estrés por el ruido de las explosiones. En resumen, la teoría de los bienes públicos (Hoppe, 2013: 385021) «es un razonamiento erróneo, ostentoso, montado en contradicciones internas, incongruencias, apelando a interpretaciones basadas en prejuicios y creencias populares asumidas, pero sin mérito científico alguno».

\section{$\mathrm{V}$}

\section{LA PROBLEMÁTICA DEL MONOPOLIO DE LA PRODUCCIÓN DE SEGURIDAD}

El monopolio de la producción de seguridad adolece de los mismos problemas derivados de la imposibilidad de cálculo económi-

${ }^{20}$ No creemos que exista tal cosa como «utilidad social» y sólo la empleamos a efectos dialécticos.

${ }^{21}$ Edición kindle. 
co que presenta una economía socialista y de los incentivos racionales que poseen sus miembros para entregar servicios deficientes al mayor coste posible. Veamos las diferencias entre el monopolio y el libre mercado de la seguridad.

\section{Contabilidad de costes}

El gobierno y su órgano de planificación central no saben cuánta seguridad debe producirse, ni qué método de producción adoptar, tampoco tienen forma racional de saber cuántos aviones, buques, helicópteros o soldados son los necesarios para atender a la defensa. No es posible determinar la ubicación física o despliegue de las fuerzas ni qué tipo de adiestramiento deben realizar éstas. Todas esas cuestiones sólo tienen respuesta atendiendo a razones de índole económica, es decir, financiera. Solo pueden contestarse (Rothbard, 2013c: 148) dentro de un mercado que funciona impulsado por el deseo de obtener ingresos y ganancias en dinero. En ausencia de mercado, no se genera la información precisa para la toma de decisiones. La racionalidad propia del cálculo económico queda sustituida por la discrecionalidad, arbitrariedad o pugna de intereses entre personas y grupos diversos. Las ineficiencias y las contradicciones son inevitables. Sirva de ejemplo la creación, en 2005, de la Unidad Militar de Emergencias (UME), que fue debida al incendio forestal que se produjo ese mismo año en Guadalajara, con 11 fallecidos ${ }^{22}$. Desde el punto de vista económico no parece muy eficiente que, tras haber recibido una larga y costosa preparación militar, los profesionales de la milicia sean «reconvertidos» para realizar funciones de protección civil, cuya naturaleza es muy distinta a la militar. Una cosa es prestar ayuda puntual en emergencias civiles y otra muy distinta desnaturalizar la misión de las fuerzas armadas. Emplear a los militares como bomberos o rescatadores tiene tan poco sentido como enviar a la guerra a los miembros de Protección Civil. La creación de la UME se debe a razones de orden político: el gobierno no era capaz de coordinar las unidades de pro-

22 Dossier UME, 2014. Ministerio de Defensa. http://www.ume.mde.es/Area_ prensa/Dossier/ 
tección civil pertenecientes a diferentes comunidades autónomas y decidió crear su propio cuerpo de protección civil. La arbitrariedad en la asignación de los recursos conduce no sólo a ineficiencias sino a conflictos internos en el seno de las organizaciones del Estado. Por ejemplo, las diferencias retributivas entre funcionarios (militares y policías) es causa frecuente de malestar que no aflora a la luz pública debido a la opacidad de sus organizaciones y a las restricciones legales de asociación y libertad de expresión. Por otro lado, tampoco es posible calcular la cantidad de impuestos que debe cobrarse para atender la seguridad ni cómo repartir ese cobro entre los ciudadanos. Bajo el régimen público de producción no existe conexión entre el pago del servicio y su consumo. No es posible calcular si la cantidad confiscada por el Gobierno - el pagoes menor, igual o mayor a la cantidad de seguridad recibida - el consumo. Sólo la intuición puede ayudarnos en el cálculo. Por ejemplo, una persona que pague elevados impuestos y que viva en un chalé aislado en el campo consume probablemente menos seguridad de la que paga; en cambio, un gobernante — que no paga impuestos, sino que los consume (Rothbard 2013b: 1911) — recibe habitualmente una elevada cantidad de protección policial de los agentes que están bajo sus órdenes directas. Bajo un régimen de monopolio estatal, la seguridad «pública» se convierte habitualmente en la seguridad «privada» de las élites políticas.

\section{Distribución espacial y temporal}

En un sistema de monopolio tampoco es posible distribuir espacial y temporalmente la seguridad de acuerdo a criterios racionales, como sería la demanda de seguridad de los consumidores, siendo aquellos sustituidos por los intereses de los propios proveedores de seguridad, de sus jefes y de otros grupos organizados de la sociedad (lobbies). Un criterio para aumentar la oferta de seguridad es la acumulación de personas en un espacio público; sin embargo, el Estado atiende por igual eventos públicos -manifestaciones políticas- que privados - eventos deportivos o artísticos con mucha afluencia de público. Y como la seguridad es un bien escaso, los policías que cuidan un partido de fútbol o un concierto, por ejem- 
plo, dejan de atender la protección de los ciudadanos en otros lugares. Vemos aquí, de nuevo, otro ejemplo que prueba la existencia de rivalidad en el consumo de seguridad. Así el gobierno, en ocasiones, beneficia a empresas privadas a expensas del resto de ciudadanos. Estas transferencias discrecionales de seguridad no serían posibles en el libre mercado de la producción de seguridad donde cada consumidor pagaría por su consumo.

\section{Incentivos}

Los incentivos racionales operan de forma contraria en el monopolio y en el libre mercado. En el caso de la defensa nacional, el gobierno otorga a los funcionarios incentivos diversos que pretenden generar conductas deseadas. Tanto en paz como en guerra, los militares son premiados con condecoraciones - algunas pensionadas- o ascensos que recompensan el valor, la abnegación y, en general, hechos notables que contribuyen a los fines del Ejército. Igualmente, el castigo se aplica severamente en caso de cobardía, deserción o traición. Pero estos incentivos positivos y negativos, que han sido creados de forma instrumental, pueden generar efectos perversos e indeseados. Recompensar el valor o por haber sufrido una herida en combate puede generar conductas temerarias en aquellos militares más ambiciosos, o dicho en términos económicos: los que manifiestan una mayor preferencia temporal. Este tipo de incentivos incrementa innecesariamente el riesgo asumido. Análogamente, los incentivos negativos pueden producir trastornos psicofísicos como la autolesión, única forma que algunos encuentran para eludir la guerra.

\section{VI \\ ¿ES POSIBLE ABOLIR EL MONOPOLIO \\ DE LA DEFENSA NACIONAL?}

Si el monopolio de la seguridad es abolido mediante la sublevación y la insurgencia - afirma Molinari- lo normal no es confiarlo a la libre competencia sino explotarlo en común por su propia cuenta 
organizando un sistema de producción comunista. La institución del Parlamento en Inglaterra y de la Asamblea Legislativa en Francia situaron el monopolio de la seguridad en manos de un productor colectivo, es decir, de un productor comunista, según la terminología del economista belga. En igual sentido se expresa H. L. Menken (Hoppe, 2004: 351): «Las revoluciones políticas casi nunca realizan sus ideales; su único e indudable efecto es la expulsión del poder de una banda de ladrones y su sustitución por otra». Así pues, mediante las revoluciones sólo se consigue cambiar de manos el monopolio de la violencia pudiendo resultar en un empeoramiento de la situación final. Todas las guerras civiles no son otra cosa que la pugna entre, al menos, dos bandos que aspiran a convertirse en el monopolio de la violencia sobre un determinado territorio. Prosigue Molinari: «Y puesto que este monopolio, por su propia naturaleza, es extraordinariamente rentable, vemos también por todas partes a las razas investidas con el monopolio de la seguridad librar luchas encarnizadas con el fin de aumentar la extensión de su mercado». Para el Estado, cada nuevo territorio conquistado aumenta los recursos naturales y la población disponible a la que poder confiscar. Por este motivo, las élites que detentan el poder intentarán por todos los medios a su alcance mantener $y$, si pueden, aumentar su monopolio territorial de compulsión y coacción. El gobierno de los Estados Unidos, casi desde sus orígenes, practicó permanentemente un expansionismo agresivo (Hoppe 2004: 317). Sensu contrario, todo Estado se opondrá naturalmente a la secesión de cualquier parte de su territorio, por pequeño que sea. Haremos aquí una digresión para justificar esta hipótesis. En primer lugar, los Estados-nación se han blindado constitucionalmente para impedir cualquier atisbo de secesión. La Constitución española de 1978 reza en su art. 2: «La Constitución de fundamenta en la indisoluble unidad de la Nación española, patria común e indivisible de todos los españoles...». La Constitución francesa de 1948 reza en su art. 1: «La nueva nación es indivisible, laica, democrática y social...». La Constitución alemana de 1949 no es tan taxativa como las anteriores: «Los alemanes, en los Länder de Baden-Wurtemberg, [...] y Turingia, han consumado, en libre autodeterminación, la unidad y la libertad de Alemania». La única excepción a la norma es el Principado de Liechtenstein donde cada 
una de las once comunas tiene reconocido el derecho de secesión ${ }^{23}$ pero este hecho per se no elude necesariamente el monopolio estatal de la fuerza. El libre mercado de la seguridad exige la renuncia del gobierno, sea éste grande o pequeño, a cualquier forma de violencia o monopolio gubernamental.

En segundo lugar, nos apoyaremos en el análisis histórico para afirmar que todo Estado querrá mantener, incluso por la fuerza, su monopolio territorial de compulsión. La formación de nuevos Estados mediante procesos de secesión ha sido secularmente violenta. Yugoslavia, a partir de 1991, se escindió en siete repúblicas: Serbia, Eslovenia, Croacia, Bosnia y Herzegovina, Montenegro, Macedonia ${ }^{24}$ y Kosovo; algunas secesiones (Eslovenia, Croacia y Macedonia) se produjeron de forma relativamente pacífica gracias a una sorpresiva declaración unilateral de independencia; en cambio, otras (Bosnia i Herzegovina y Kosovo) se culminaron tras sendos conflictos con Serbia. La URSS, tras el colapso del comunismo en 1989, se desintegró en veinte naciones: la Federación Rusa otras 19 Repúblicas, cuatro de las cuales son Estados no reconocidos en la actualidad. Otras naciones tienen actualmente tensiones secesionistas: China, Canadá (Quebec), Reino Unido (Escocia), España (Cataluña y País Vasco), Italia (Liga Norte, Venecia, Tirol del Sur, Sicilia), Francia (Córcega), Bélgica (Flandes y Valonia), Ucrania, etc. Son una excepción los Estados que han permitido procesos secesionistas democráticos: Canadá, en 1980 y 1995, y Reino Unido, en 2014. Aun así, en estos procesos «pacíficos» es recurrente el empleo de amenazas veladas de parte de los gobiernos y entes supranacionales: los nuevos Estados quedarían automáticamente excluidos de las instituciones europeas como la Unión política y monetaria, la banca no tendría acceso a la liquidez del Banco Central Europeo, etc. Son insólitos los casos como el de Checoslovaquia que, en 1993, se escindió pacíficamente y de mutuo acuerdo en dos repúblicas, Chequia y Eslovaquia, volviendo al statu quo previo a la Primera Guerra Mundial. A pesar de

${ }^{23}$ Art. 4.2. Individual comunes have the right to secede from the State.

${ }^{24}$ Inicialmente llamada FYROM: Former Yugoslav Republic of Macedonia. Grecia mantiene actualmente un contencioso con Macedonia a cuenta del nombre ya que también existe una región griega llamada Macedonia. 
todos los procesos de secesión que se dan continuamente en el mundo, todos los nuevos estados que surgen mantienen, por pura necesidad, los monopolios de coerción y compulsión, ya con fuerzas armadas o, en su defecto, con fuerzas policiales. Algunas excepciones a la norma son: a) Los Amish ${ }^{25}$ : son pacifistas y rechazan toda forma de violencia incluso la realizada en legítima defensa. b) Los gitanos: proveen su propia seguridad apoyándose en los vínculos familiares y no suelen acudir a la Policía. Amish y gitanos viven en comunidades regidas bajo ley privada que, a su vez, viven insertas en los territorios estatales y sometidos a la jurisdicción de los gobiernos. c) Autodefensas de Méjico: comunidades rurales que han constituido milicias ante la incapacidad del gobierno para proveerles protección; aquí, las fuerzas de seguridad privadas y públicas conviven sin relación jerárquica entre ellas. d) Somalia: es el único caso de Estado formalmente constituido donde el monopolio de seguridad fue abolido en 1991 y no ha sido reemplazado por otro monopolio similar. Los clanes en Somalia, desde hace 24 años, viven en una «critarquía» (Van Notten, 2006: 188) o «gobierno de los jueces», una sociedad sin Estado donde los servicios de seguridad y justicia se producen en libre competencia y sometidos a la Ley consuetudinaria somalí o Xeer.

\section{VII}

\section{EL LIBRE MERCADO DE LA SEGURIDAD: ANÁLISIS PROSPECTIVO}

Consideramos remota la plausibilidad del advenimiento, aún a pequeña escala, de un orden social laissez faire y su corolario, la producción de seguridad en libre competencia. Sin embargo, los micro Estados europeos pueden ayudarnos en la tarea prospectiva de vislumbrar sociedades más libres y prósperas. El primer ejemplo es Ciudad del Vaticano, un minúsculo enclave en Roma donde reside la Santa Sede, una teocracia electiva cuya ley privada «Código Canónico» se superpone a la legislación de otros Estados. La Santa Sede

25 Las comunidades Amish cuentan con alrededor de 230.000 personas ubicadas en 22 asentamientos situados en los Estados Unidos de América y en Ontario, Canadá. 
admite el principio de secesión individual y cualquier católico, religioso o seglar, es libre de abandonar la Iglesia católica. La Santa Sede obtiene sus ingresos económicos sin apelar a la coacción si bien es cierto que, indirectamente, mediante tratados bilaterales, acepta dinero confiscado por terceros Estados. Otros micro Estados europeos -Mónaco, Andorra y Liechtenstein- se caracterizan por poseer una baja fiscalidad (refugios fiscales) y no disponer de fuerzas armadas permanentes. Todos los micro Estados monopolizan la policía y la justicia, y algunos ${ }^{26}$ han externalizado su defensa militar encomendándosela a sus vecinos. Observamos una correlación inversa entre dimensión territorial del Estado y coacción gubernamental. Los Estados más pequeños disponen de fuerzas armadas reducidas o no disponen en absoluto de ellas; son menos agresivos (fiscalmente) dentro de sus fronteras. Por tanto, la aplicación del principio de secesión indefinida sería un elemento favorable en nuestra búsqueda de un sistema social con producción privada de seguridad.

En segundo lugar, todo gobierno tiende a preservar el statu quo político y se opondrá con todos los medios a su alcance, incluido el empleo de la violencia, a cualquier intento de secesión ${ }^{27}$. La razón es evidente: la clase que ostenta el poder político (Michels, 2003: 43), considerada en su conjunto, nunca cede espontáneamente sus posiciones ventajosas. Y la existencia de cuerpos de seguridad privados que escapen al control y dominio del poder político (Llamas, 2010: 1) constituiría una amenaza directa a la naturaleza estatal. Cuando un Estado sufre tensiones secesionistas su diplomacia trabaja para que el máximo número de Estados apoye su visión y se mantenga así el statu quo internacional. En este sentido, no siempre es posible obtener un apoyo global. Además, va en el propio interés del resto de Estados que no existan demasiados precedentes secesionistas. La naturaleza del Estado es expansiva y toda pérdida de territorio se percibe como una amenaza mientras que cualquier incorporación es bienvenida. La reciente secesión de Crimea, aprobada en referéndum el 17 de marzo de 2014, es un buen ejemplo de este doble rasero, lo que es malo para Ucrania es bueno para Rusia. En el supuesto de

${ }^{26}$ Ciudad de Vaticano: Italia; Mónaco: Francia; Andorra: España y Francia; Liechtenstein: Suiza.

27 Ya hemos visto que Liechtenstein es la única excepción. 
que asistamos a futuros procesos de secesión política en países avanzados (Quebec, Escocia, Cataluña, Norte de Italia, etc.) es previsible que los nuevos Estados dediquen menor cantidad de recursos económicos a la defensa e incluso que se contenten sólo con fuerzas policiales y de seguridad fronteriza. Esto también sería aplicable a las secesiones en cadena, por ejemplo, Cataluña respecto de España y el Valle de Arán respecto de Cataluña. Actualmente veinticinco países en todo el mundo ${ }^{28}$ no poseen fuerzas armadas permanentes.

En tercer lugar, no podemos descartar la cesión parcial de soberanía de un Estado para la fundación de sociedades libres como los proyectos free cities (ciudades libres bajo estatuto) o floating cities (ciudades flotantes sobre el mar) que sirvan de polos de desarrollo económico para los Estados anfitrión. Estas iniciativas chocan, por lo común, con la oposición de los gobiernos pues no son vistas como dinamizadoras de la economía de la región sino como una peligrosa competencia fiscal. En 2013, el Congreso Nacional de Honduras aprobó una ley orgánica ${ }^{29}$ que regula las Zonas de Empleo y Desarrollo Económico (ZEDE), algo que posibilita la creación de territorios con un elevado grado de autonomía política y económica. En la medida en que estas iniciativas tengan resultados positivos podremos asistir a un incremento del número de ciudades libres en el mundo y a una incipiente provisión de defensa y seguridad privadas. Siempre quedan incógnitas por resolver: ¿es probable que una nación armada invada otra pequeña y desarmada? Si ambas naciones poseen gobiernos democráticos la probabilidad (histórica) de que esto suceda es baja. No creemos probable que España o Francia conquisten militarmente Andorra o Mónaco. En cambio, los gobiernos de las naciones democráticas de grande y medio tamaño son especialmente agresivos con las naciones no democráticas. En cuarto lugar, el empleo de la guerra irregular, incluido el terrorismo, como medio de represalia de los Estados pequeños frente a la intervención militar de los más potentes ejerce un efecto disuasorio so-

${ }^{28}$ Barbados, Dominica, Granada, Haití, Islandia, Kiribati, Islas Marshall, Isla Mauricio, Micronesia, Nauru, Palaos, Panamá, Islas Salomón, Samoa, San Cristóbal y Nieves, Santa Lucía, San Vicente y las Granadinas, Tuvalu y Vanuatu, Andorra, Liechtenstein, Mónaco, San Marino y Ciudad del Vaticano.

${ }^{29} \mathrm{http}: / /$ www.tiempo.hn/portada/noticias/aprueban-ley-organica-de-nuevas-ciudades-modelo 
bre el intervencionismo militar. En quinto lugar, asistimos a una reducción global de los arsenales y gastos de defensa militar, así como a una mayor privatización de la seguridad. Por ejemplo, entre 2009 y 2012, de los 34 países que integran la $\mathrm{OCDE}^{30}$, 25 han reducido su gasto militar, 7 países lo han mantenido y solamente dos países - Méjico y Polonia- lo han incrementado.

Otro hecho observable es la progresiva reducción de la conscripción en el mundo. No apreciamos motivos para que esta tendencia se invierta. Sin embargo, Noruega, país que mantiene el servicio militar obligatorio para el hombre, ha ampliado en 2015 esta prestación a la mujer. La medida, más que una necesidad genuina de la defensa, parece obedecer más bien a políticas igualitarias: «se trata de dar a mujeres y a hombres igualdad de derechos y obligaciones», afir$\mathrm{ma}^{31}$ la ministra de defensa, Ine Eriksen Søreide.

A pesar de que la producción pública de seguridad disminuye a la par que la seguridad privada aumenta, esta última seguirá bajo estrecha supervisión y control de los gobiernos y estos no permitirán que los ciudadanos dejen de pagar impuestos para sufragar la defensa. La seguridad privada, por tanto, será complementaria y subordinada a la estatal. Por último, es improbable que los gobiernos normalicen y faciliten el uso privado de armas de fuego ya que ellos mismos se han encargado de transmitir a la población la peligrosidad de esta medida. Incluso en EEUU, país cuya Constitución (II Enmienda) ${ }^{32}$ reconoce expresamente el derecho al uso de armas, existen actualmente intentos gubernamentales para desarmar a la población.

\section{VIII CONCLUSIONES}

1. La crítica que hace Molinari del monopolio estatal de la producción de seguridad (Rothbard, 2013:1060) es «la culminación ló-

${ }^{30} \mathrm{http}: / /$ datos.bancomundial.org/indicador/MS.MIL.XPND.GD.ZS. Datos referidos a \% respecto de PIB.

31 http://www.lavanguardia.com/internacional/20141018/54418028513/noruega-obligara-mujeres-realizar-servicio-militar.html

32 A well regulated Militia, being necessary to the security of a free State, the right of the people to keep and bear Arms, shall not be infringed. 
gica de sus propias ideas de laissez-faire». La idea de Molinari es desafiante porque supone un ataque frontal a quienes justifican la existencia del Estado, ya sea por sus ideas, ya sea por sus intereses.

2. No encontramos razones económicas que justifiquen la necesidad del monopolio estatal de la producción de seguridad. Al igual que el resto de bienes económicos, la seguridad puede quedar sometida a la libre competencia. Los argumentos estatistas se pueden rebatir desde distintas ópticas: ontológica, biológica, monopolio natural, teleológica, histórica, lógica, marginalista, antropológica y funcional-institucional. El argumento económico predominante - la teoría de los bienes públicostambién puede ser criticado pues, como hemos demostrado, siempre existe rivalidad en el consumo de seguridad, también existen formas de excluir del servicio a los que no pagan y, en todo caso, estos últimos no son considerados por los consumidores como un problema relevante. Que el gobierno sea incapaz de resolver las cuestiones de rivalidad y exclusión no significa que el mercado no pueda hacerlo.

3. La principal deficiencia del monopolio de la seguridad se deriva del axioma de la imposibilidad del cálculo económico en una economía socialista. El órgano central de planificación no puede hacerse con la información necesaria para coordinar adecuadamente los procesos sociales y la función empresarial queda eliminada.

4. El Estado tiene una naturaleza coactiva y expansiva. Mayores gastos en defensa militar no aumentan concomitantemente la protección del ciudadano y merma la capacidad productiva de la nación. Según el profesor Robert Higgs ${ }^{33}$ : «el Estado es la institución más destructiva que los seres humanos jamás hayan concebido». Los gobiernos democráticos no suelen agredirse entre sí pero ello no implica, en modo alguno, una menor resistencia a cualquier proceso secesionista que será visto como una merma de su monopolio territorial de compulsión y coacción.

33 https://www.juandemariana.org/ijm-actualidad/pildoras-de-libertad/la-actualidad-de-robert-higgs 
5. Sin el monopolio de la fuerza y su corolario, la confiscación, el Estado-nación tal vez no desaparezca completamente pero sufrirá una reducción severa en tamaño, funciones y poder. Posibles supervivientes serían teocracias, monarquías hereditarias y repúblicas de pequeño tamaño con recursos propios y/o financiados privadamente.

6. Con algunas pocas excepciones -Amish, gitanos, autodefensas mejicanas y somalíes- la producción de defensa en régimen de monopolio público es un hecho jurídicamente consolidado y socialmente admitido. No creemos que este escenario cambie a medio y largo plazo debido al creciente consenso socialdemócrata, es decir, a la aceptación social del mayor protagonismo del Estado en los ámbitos público y privado. El único resquicio de producción privada de seguridad, en régimen de libre competencia, sólo parece posible tras la materialización de los proyectos free cities o ciudades libres bajo estatuto.

\section{REFERENCIAS BIBLIOGRAFICAS}

BAstos, M. (2005): «iPuede la intervención estatal ser justificada científicamente? Una crítica». Procesos de Mercado. Revista europea de economía política, Vol. II, $n^{\circ} 1,2005, \mathrm{pp} .11-51$.

BAstias, F. (1948): «El Estado», Diario de Debates, Número de Septiembre.http://bastiat.org/es/El_Estado.html

BENSON, B. (2000): Justicia sin Estado, Madrid, Unión Editorial.

BöHM-BAWerK, E. (1998), Teoría Positiva del Capital, Madrid, Aosta.

CalzadA, G. (2006): «Gustave de Molinari (1819-1912)». La Ilustración Liberal, $n^{\circ} 29$.

CHodorov, F. (2002): The Income Tax: Root of all Evil, Mises Institute (online edition).

Constituciones: EEUU (1787): Principado de Liechtenstein (1921), Francia (1948), Alemania (1949) y España (1978).

Feito, L. (2010): «Hacia una mejor comprensión del papel de la naturaleza en los debates bioéticos». VERITAS, Nº 23, pp. 111 a 129.

HART, D. (1982): «Gustave de Molinari and the Anti-statist Liberal Tradition - Part III». The Journal of Libertarian Studies, Vol. VI, $N^{o} 1$. 
HAYeK, F. (2014): Derecho, Legislación y Libertad, Madrid, Unión Editorial $\left(2^{\mathrm{a}} \mathrm{Ed}\right.$.)

HoвBEs, T. (2011): Leviatán, Madrid, Alianza Editorial.

Hoppe, H. (2004): Monarquía, democracia y orden natural, Madrid, Gondo

- (2003): The myth of national defense: essays on the theory and history of security production, Alabama, Ludwig von Mises Institute (Kindle).

- (2013): Una Teoría del Socialismo y el Capitalismo, Kindle, Innisfree.

HuerTA DE SOTO, J. (2010): Socialismo, cálculo económico y función empresarial, Madrid, Unión Editorial [ 4 a edición].

Kennedy, P. (1989): Auge y caída de las grandes potencias, Barcelona, Plaza y Janés.

Kunn, T. (2006): La Estructura de la Revoluciones Científicas, Méjico, FCE.

Llamas, M. (2010): «La seguridad, el gran monopolio estatal». Instituto Juan de Mariana. https://www.juandemariana.org/ijm-actualidad/analisis-diario/la-seguridad-el-gran-monopolio-estatal

MankiW, G. (2007): Principios de Economía, Madrid, Thompson.

MARTínez, C. (2013): La Teoría Evolutiva de las Instituciones, Madrid, Unión Ed., $2^{\text {a }}$ ed.

Michels, R. (2003): Los Partidos Politicos II, Buenos Aires, Amorrortu. Mises, L. (1980): La Acción Humana, Madrid, Unión Editorial [10 edición 2011]

— [1922] (1959): Socialismo, Nueva York, WBF (3 ${ }^{\text {a }}$ edición castellana) MolinARI, G. (1848): «Sobre la producción de seguridad» (traducción de Gabriel Calzada). Liberalismo.org (http://www.liberalismo.org/articulo/261/240/produccion/seguridad/)

Negro, D. (2014): Conferencia: «El enemigo, el Estado», Instituto Juan de Mariana. https://www.youtube.com/watch?v=sEFi6U4wUDc

NotTen, M. (2006): The Law of the Somalis, New Jersey/Eritrea, The Red Sea Press, Inc.

Popper, K. (2010): La Sociedad Abierta y sus Enemigos, Barcelona, Paidós Surcos.

Rallo, J. (2014): Una Revolución Liberal para España, Barcelona, Deusto. Rothbard, M. (2009): La ética de la libertad, Madrid, Unión Editorial (kindle). 
— (2013a): Historia del Pensamiento Económico, Madrid, Unión Editorial,

- (2013b): Poder y Mercado, Guatemala, Universidad Francisco Marroquín.

- (2011): El Hombre, la Economía y el Estado. Vol. I, Madrid, Unión Editorial.

- (2013c): El Hombre, la Economía y el Estado, Vol. II, Madrid, Unión Editorial.

Rummel, R. (1994): Death by Goverment, New Jersey, Transaction Publishers, (kindle)

SAmuelson, P. y Nordhaus, W. (2005): Economía, Méjico, McGraw Hill (18 edición)

Schumpeter, J. (2012): Historia del Análisis Económico, Barcelona, Ariel.

Tovar, C. (2004): «Lex Mercatoria Internacional como instrumento de regulación de las relaciones privadas internacionales», Agenda Internacional, Año XI, N²1, pp. 157-176. 